AC 2012-4616: PROFESSIONAL DEVELOPMENT FOR SOPHOMORE ENGINEERING STUDENTS

Dr. Edward F. Glynn P.E., Villanova University

Ed Glynn is an Assistant Professor in the Department of Civil and Environmental Engineering at Villanova University.

Prof. Frank E. Falcone, Villanova University 


\title{
Professional Development for Sophomore Engineering Students
}

\begin{abstract}
The development of project management skills and interaction with the regional professional engineering community are integral parts of Civil Engineering Fundamentals, a required fall semester sophomore course in the civil engineering curriculum at Villanova University. Project management skills are introduced through a lecture format and rigorously emphasized by assigning students as Project Managers (PMs) during the course. Their performance as PMs is graded by their instructors and both quantitatively and qualitatively evaluated by their peers. Interaction with the regional professional engineering community is addressed through a Mentors Program by assigning students to practicing civil engineers who are graduates of the same engineering program and who have volunteered to participate as mentors for these students. Students interact with these professionals via email during the semester and submit written summaries for each of these interactions.
\end{abstract}

\section{Introduction}

The Department of Civil and Environmental Engineering at Villanova University has recently revised its curriculum. In particular, the Department reduced the number of credits in the curriculum by consolidating several related topics into a few key courses. One of these courses, Civil Engineering Fundamentals, is taught in the fall semester of the sophomore year and serves as an introduction to the engineering program. The course includes three 50-minute lectures and one 3-hour laboratory session per week over a 14-week semester. There are two sections of the course, each of which has between 20 and 30 students. Fundamentals is designed to help sophomores develop many analytical, interpretive and field-based skills and procedures used in civil engineering practice. The course includes plane surveying, map interpretation, laboratory testing, numerical methods, statistics and probability as well as other technical topics. The course also introduces sophomores to the professional practice of civil engineering. The professional practice component of Fundamentals has two major features, exercises in project management skills and a mentoring program. This paper focuses on these two professional practice features.

Fundamentals has been taught twice in its current format: in fall semesters of 2010 and 2011. Both the management exercises and mentoring program have evolved as the instructors learned from their classroom experiences as well as from the comments of students and their mentors.

\section{Developing Project Management Skills:}

In addition to developing strong technical skills with the ability to think through technical problems in a regimented and organized approach, engineering students must also develop the ability to manage projects (people, schedules and resources) such that the quality of their finished products meets or exceeds client expectations. This goal is, indeed, the definition of 'quality'- meeting or exceeding clients' expectations.

Simply offering the concept of effective project management (PM) to engineering students in a lecture format, regardless of their position in a four-year undergraduate engineering curriculum, 
seems to be ineffective because the concept is neither practiced nor measured in that format other than through written testing. In addition, simply dividing classes into groups of students for the completion of laboratory or other related assignments in order to address PM, is ineffective because such assignments, in and of themselves, do not stress the importance of effective project management. Does this approach define the goal of effective project management or simply assign students to that role? The goal of effective project management is to provide 'quality' to clients or, in an academic setting, to instructors by delivering a product which may be considered greater than the sum of its parts.

In an academic setting, effective project management creates an environment within the group of students which encourages creative thought, rewards the self-driven sharing of ideas and concludes with a final product which is of a quality much higher than that achievable by any one member of the group individually. The academic challenge for engineering faculty is to carefully craft a course, or a suite of courses, through which these concepts are introduced, practiced, measured and honed. One of the goals of Civil Engineering Fundamentals is to attempt to address that challenge through an organized and measurable approach.

As noted in Figure 1, Fundamentals is structured around five modules, each of which has a major written or oral report associated with it. Four of these modules are technical in that groups of students are required to address and complete a technical project. For each of these projects, a Project Manager is assigned.

\begin{tabular}{|c|c|c|c|}
\hline Module & Theme & Topics & Project \\
\hline 1 & Surveying Skills & $\begin{array}{l}\text { - Use of Transit } \\
\text { - Plane Surveying } \\
\text { - Balancing Data }\end{array}$ & Closed Traverse \\
\hline 2 & Mapping \& Field Work & $\begin{array}{l}\text { - Reading Contour Maps } \\
\text { - Gaging Streams } \\
\text { - Rational Formula }\end{array}$ & Valley Creek Study \\
\hline 3 & Probability Concepts & $\begin{array}{l}\text { - Axioms of Probability } \\
\text { - Density Functions } \\
\text { - Monte Carlo Simulation }\end{array}$ & $\begin{array}{l}\text { Reliability } \\
\text { Assessment of a } \\
\text { Howe Truss }\end{array}$ \\
\hline 4 & $\begin{array}{l}\text { Numerical Methods \& } \\
\text { Data Reduction }\end{array}$ & $\begin{array}{l}\text { - } \text { Curve Fitting } \\
\text { - Roots of Equations } \\
\text { - Numerical Integration }\end{array}$ & $\begin{array}{l}\text { Materials Testing \& } \\
\text { Hydraulics } \\
\text { Experiment }\end{array}$ \\
\hline 5 & $\begin{array}{l}\text { Professional } \\
\text { Development }\end{array}$ & $\begin{array}{l}\text { - Presentation Skills } \\
\text { - Engineering Ethics } \\
\text { - Mentoring Program }\end{array}$ & Group Presentation \\
\hline
\end{tabular}

Figure 1. Learning Modules in Civil Engineering Fundamentals 
The fifth module directly addresses the broad area of professional practices in engineering through a structured Mentors Program and also through the development of project management skills. The fifth module is implemented as follows:

- Early in the course, students are given a lecture on the importance of developing both leadership and management skills as part of their overall undergraduate education. The differentiation between leadership (people oriented) and management (process oriented) is introduced and stress is placed on management and the development of project management skills. A deeper, serious and more vibrant focus on leadership, which is 'people focused' is addressed in a course entitled Professional Practices in Engineering which these same students must take as seniors. At the conclusion of this initial lecture, while still in class, students are asked to provide a list of the attributes \& characteristics of a 'good project manager'. They are asked to answer the question,

If you are working in a group of individuals and you feel that you have a good project manager, what are the attributes and characteristics continuously displayed by that project manager which leads you to conclude that he/she is 'good' in that role?

Each student must prepare a list of attributes and characteristics. These lists are collected by the instructors to be utilized later in the course.

- Each section of the course is randomly divided into groups of four or five students. These groups remain intact through the entire semester. The current phonetic alphabet (Alpha, Bravo, Charlie, Delta. etc.) is used for group designations. The first individual in each group is assigned as PM for the project associated with the first course module. The second student listed in each group serves as the PM for the project associated with the second course module and so forth. The course is structured such that all students will serve in the role of PM at least once. The ideal number of students enrolled in each section of this course is 25 because there are five modules and each student must serve in the role of PM least once.

- In order to apply an incentive for students serving in the project management role to implement their own list of good project management attributes and characteristics and to apply the lessons taught in the introductory lecture described above, a 'double grade' is assigned to the PM for the final project report or oral presentation associated with a particular project. For example, if a project report earns a grade of $84 \%$, then the PM will receive two $84 \%$ grades to be factored into his/her overall course grade.

- Following the completion of a course module and the submission of the project report or completion of the oral presentation associated with that module, students in each group have an opportunity to evaluate the performance of their PMs by comparing the actual work of their PMs to the attributes and characteristics which the PM listed earlier in the course. In other words, the effectiveness of the PM is measured by his/her peers according to his/her own definition of a 'good' PM. 
- At the same time that group members are evaluating the effectiveness of their PM, the PM has an opportunity to comment on the work contributions of each member of the group by completing a sheet highlighting the efforts of each of the group members. The sheet which they complete is prepared in such a way as to solicit constructive feedback from which continuous improvement may be made.

- The two types of evaluations described above help lead the students to a fuller understanding of the importance of learning and focusing on PM skills by having them address, first hand, their own work in the course while it is still fresh in their minds. Project Management is not presented in Fundamentals as an abstract concept to be remembered and applied sometime after graduation. Nor, is it presented through a series of lectures and lecture notes which may have no near-term meaning to sophomore students in engineering because they may not view themselves in management roles for many years to come. Instead, PM is presented as essential, near term, real and 'grade based'. The assigned PM has 'skin in the game' and will be measured in that role by his/her instructors and perhaps, more importantly, by his/her peers. Once again, he/she will receive a 'double grade' for the project for which he/she serves as PM. It is worth noting that well organized, well led and well managed engineering firms, as well as many other well led organizations, apply similar teaching and learning techniques for staff members in order to develop and improve long term effective PM skills. Organizations, in turn, benefit from such improvements as measured by the number of satisfied clients and increased revenue. The point here is that introducing and teaching effective project management skills early in an undergraduate engineering curriculum can reap substantial rewards for graduating engineering students early in their careers and, by extension, also for the organizations that choose to employ them.

- As stated earlier, the first four course modules are built around technical projects. The fifth module, however, addresses professional development skills directly. For the fifth module, the groups of students, working together as groups throughout the semester, must present one of the technical projects associated with the first four modules in a structured oral presentation which is recorded, viewed by the students, critiqued and graded. A PM is assigned and, once again, that PM receives a double grade for his/her efforts.

- Prior to the groups giving these oral presentations, the class is provided with a lecture stressing the importance of developing good communication and presentation skills. The notes associated with this lecture provide a clear structure, used in the engineering marketplace, through which an effective and 'results oriented' oral presentation can be developed and given. In addition to stressing the importance of developing a strong and deep understanding of the technical issues to be presented, this lecture also stresses the importance of conveying key technical concepts, project results, voice projection, body language, appropriate dress, the use of power point projections, graphs, tables, figures, etc. It also stresses the importance of solid preparation through continual practice. This effort is measured through strict compliance with a prescribed presentation duration of 16 to 18 minutes. Presentations that vary from this requirement are heavily penalized. The PM, of course, receives double the final grade. Therefore, his/her project management 
skills, developed during the semester through work on the other four modules, will be on full display during these oral presentations. Once again, PMs and group members will have the opportunity to evaluate their performance in their oral presentations as described above.

- Students view their recorded presentations twice. The first viewing is played without interruption. During the second viewing, however, instructors and group members are free to interrupt the recorded presentation in order to highlight presentation skills or shortcomings and/or to offer constructive criticism regarding aspects of presentation skills.

- The grading of the oral presentations is carefully crafted. 50\% of that grade is assigned by the instructors and 50\% is assigned by all of the students in their respective section of course. The portion assigned by the students is captured through the completion of individual presentation evaluation sheets and also by their completion of a 'presentation comparison' sheet. In order to address the issue of grade inflation among students (they tend to give each other very high oral presentation grades regardless of effort), students must compare presentations which they have observed. For example, if students view five presentations, they must rank those presentations from best to worst, i.e., from one to five, respectively. They do not rank or evaluate their own presentation. Following the conclusion of all oral presentations, the instructors compile this comparative data and assign the 50\% student portion of the final oral presentation grade as follows: $\# 1 \rightarrow$ $95 \%, \# 2 \rightarrow 90 \%, \# 3 \rightarrow 85 \%, \# 4 \rightarrow 80 \%$ and $\# 5 \rightarrow 75 \%$. Finally, $50 \%$ of the instructors' grade and $50 \%$ of the students' grade are added to determine the oral presentation grade.

- Near the completion of the course, the attributes and characteristics sheets originally prepared and submitted by each student, but now including all of the comments from their group members evaluating the student's performance as PM, are complied and given back to the students. Therefore, at the conclusion of the course, students have a clear record of their individual performance as PMs as measured against their own initial list of the attributes and characteristics of a 'good' PM. This seems to be an extremely effective summary document as part of this approach to introducing, stressing and measuring project management performance.

\section{Student Reflections on Project Management}

The Final Examination in Civil Engineering Fundamentals contained a 6-point bonus question that focused on issues associated with the project management aspects of the course. The students were alerted to these questions one week prior to the examination. The three issues, along with a summary of 'common thread' responses, are as follows:

a. In your role as Project Manager, list and briefly discuss three skills that you developed and displayed well.

- Organizational skills

- Management skills 
- Listening \& asking questions

- Effective communication skills

- Developing perseverance \& patience

- Effective time management

- Delegation skills

- Speaking skills

- Developing a strong work ethic

- Understanding accountability

b. In your role as Project Manager, based on your own experience and on input from your group members, list and briefly discuss three areas in which you need to improve.

- Set up a realistic meetings schedule.

- Clearly assign tasks as soon as possible.

- Be more assertive.

- Focus on quality not only on quantity.

- Don't procrastinate.

- Establish an 'errors checking' procedure.

- Display trust in the group.

- Improve delegation skills.

- Balance the workload among group members.

- Display continual attention to details.

- Be more accessible.

- Make deadlines 'real'!

- Seek out help from instructors as necessary.

- Allow ample time for review before report submission.

- Don't do all of the work myself - delegate!

c. Based on your work in groups during this semester and on the summary input that you received from the members of your group, list four specific suggestions that you would offer, not as a PM but as a group member, that would have made your group much more effective.

- Discuss individual problems more.

- Focus on 'small' deadlines instead of only major deadlines.

- Meet early and often.

- Focus on 'creativity', not only on the prescribed assignment.

- Ask for help when necessary.

- Check each others' work.

- Carefully proofread the final report before submission -- at least two group members should be involved in the proofreading.

- Address intra-group 'conflict management' early.

- Encourage constructive criticism.

- Become a true 'listener'. 
- Establish at least two acceptable forms of communication among all group members.

- Further develop delegation skills.

Through this overall, applied and interactive approach to project management, the instructors feel that the importance of developing project management skills early in the undergraduate curriculum is effectively stressed. It is clearly recognized by the instructors that the development of effective, long term project management skills, which can be utilized throughout an individual's professional career, are not perfected in one course or during a four- year undergraduate curriculum. But, beginning to address this issue at the sophomore level and continuing to stress it throughout the undergraduate curriculum will, hopefully, establish a strong 'project management skills foundation' upon which graduating engineering students can build a strong, quality oriented career.

\section{Mentoring Program}

The Mentoring Program (MP) was designed to have every student in Civil Engineering Fundamentals interact with a former graduate of the Department of Civil and Environmental Engineering. The Mentoring Program was developed in the summer of 2010 when the authors asked Villanova's Alumni Relations Office to send an email to all the Departmental alumni/ae in its data base. The email asked if the individual would be willing to participate in a Mentoring Program wherein he/she would be contacted several times during the fall semester by a sophomore who would inquire about the graduate's professional experiences. Within a week, over 120 alumni/ae responded.

The inaugural Mentoring Program occurred during the fall 2010 semester, the first time Fundamentals was taught, with 48 students in two sections. The fall 2010 MP was a learning experience for the faculty as well as for the students. The students contacted their mentors via email with specific questions three times during the semester. There was a four-week interval between emails.

The first email served essentially as an ice-breaker:

1. Introduce yourself as a student in Civil Engineering Fundamentals.

2. Ask your Mentor the following questions.

a. How did you choose engineering as your undergraduate major in college?

$b$. Do you find that you undergraduate engineering education prepared you well for your professional career?

c. Is your career path following a technical or a leadership/management path?

d. As we begin our dialogue, can you offer some initial ideas or suggestions, while I am still in college, that might help me begin my engineering career? 
The second email focused on teamwork skills:

1. How would you establish a group of individuals to work as a Project Team such that each individual is motivated to do his/her best all of the time?

2. How do you address the issue of Conflict Resolution in your organization?

3. Is there a formal system established in your organization to address Conflict Resolution? If so, could you briefly explain it? If not, do you apply your own concept and ideas to deal with these types of problems? Could you briefly explain your approach?

The last email addressed the issue of unethical behavior in the engineering profession and/or in the workplace.

1. What routine business practices, on a day-to-day basis, can lead to unethical behavior in the engineering profession and/or in the workplace?

2. Can you offer a specific example of such routine business practices?

3. Can you identify a specific project or program that you're familiar with that suffered consequences (technical, financial, environmental, etc.) as a result of unethical behavior in the engineering profession and/or in the workplace?

The interaction between the students and their mentors and the enthusiasm of the mentors easily met expectations. The questions seem to address issues that piqued the students' interest. There was a lecture session devoted to the MP wherein the students volunteered to share the mentors' comments. However, the logistics of the MP were untenable. The number of volunteers was so large that the instructors decided to assign two mentors to each student, a recent (1 to 10 year) graduate and a seasoned (10-30 year) graduate. It became very difficult to keep track of the emails to verify the student's participation in the program. The course had a Graduate Assistant (GA) who spent 6 hours per week on grading and other administrative duties. Despite the help of the GA, the record keeping became almost overwhelming. The instructors had several additional concerns about the Program:

- $\quad$ There was no explicit portion of the course grade assigned to the Mentoring Program. The three emails counted as a single quiz which represented less than $3 \%$ of the course grade. The small percentage was not reflective of the value which the instructors placed on the MP, but the students may have had a different perception.

- $\quad$ Virtually every student received three responses, but there was no mechanism in place to ensure the students actually read and assimilated the information. The students merely forwarded the mentors' emails to the GA in order to get credit.

- $\quad$ The MP did not have any closure. There was no requirement or even opportunity within the course for the students to reflect on and summarize what they learned from their mentors.

The second edition of the MP (fall semester, 2011) attempted to address these concerns. Each of the 53 students was assigned a single mentor. Alumni volunteers who were not used during the fall 2010 program were the first to be assigned 2011 students. The questions were essentially the 
same as those used the previous year. However, there were some significant changes in the administration of the MP.

- The Mentoring Program constituted $10 \%$ of the course grade. The instructors noted this point in reviewing the course syllabus during the first meeting. The MP was clearly an important component of Fundamentals.

- A student had to provide a one-page summary of the mentor's comments for each of the three emails.

- A student had to send electronic copies of (a) his/her email, (b) the mentor's response and (c) the summary to the GA. The GA, in turn, placed the copies in electronic files and kept track of the submittals on a spreadsheet.

- Students had to submit hard copies of their three summaries to the instructors prior to the lecture session that was devoted to summarizing the MP. The instructors picked a sampling of particularly interesting responses and asked the respective students to share their mentors' comments with the class

- The last quiz of the semester included the following 10-point bonus question:

Regarding this semester's Mentors Program, briefly state what you've learned in the following categories.

a. Professional Career Planning

b. Effective Team Dynamics

c. Ethical and Unethical Behavior in the Engineering Profession

The students were alerted to the bonus question several lectures prior to the quiz.

A few items deserve further clarification:

- Students earned three points for each of the three responses and the associated summaries. They earned the tenth point by attending and participating in the lecture session that summarized the MP. Students were not penalized if their mentors failed to respond to one of their requests. In the isolated instances where this occurred, the student's initial email documented his/her intent and secured the three points.

- A mentor who failed to respond to the first email was sent a second request and, in the absence of an immediate reply, was replaced with a new mentor.

- As indicated earlier, the three emails were spaced at approximately four-week intervals. Typically, the students were expected to send their emails within a week of receiving the instructions. The mentors were asked to respond within a week. Finally, the students had a week to prepare and submit their summaries. There was some flexibility in the schedule, but students could not combine questions from different mailings.

- Some mentors preferred to talk to the students on the phone. In that case, students were asked to have their mentors send a very short ( 1 or 2 sentence) email noting their conversation. The student still had to prepare a summary based on the phone conversation. 
- Each student had access to the portion of the GA's spreadsheet that summarized the student's work in the MP. The student had an opportunity to submit any missing documentation, i.e., emails or summaries, as long as the documents were dated prior to the appropriate deadline.

\section{Results of Mentoring Program}

Virtually all of the students in Fundamentals actively engaged in the Mentors Program. 44 of the 53 students in the course earned the full $10 \%$ of the course grade assigned to the MP. Four students earned $9 \%$ because they failed to submit one summary. The remaining five students earned between $2 \%$ and $8 \%$. Two of these five students earned $4 \%$ and $2 \%$, respectively. These last two students gained minimal profit from the MP program, other than perhaps the lecture session devoted to the MP, which had full attendance.

The statements listed below are a sampling of the students' comments that summarize what they learned in the Mentoring Program. The statements are culled from the bonus question on the last Fundamentals quiz.

a. Professional Career Planning

- Follow your passion.

- Master the fundamentals because most of the things you come across in the engineering world will be new to you.

- The mindset and problem solving techniques, not necessarily specific methodologies, are important.

- An engineering degree prepares you for almost any other career path you may choose.

- Take non-engineering courses to develop a more rounded background.

- Keep old text books and focus on developing experience via internships.

- Take business and project management classes.

- Take the Professional Engineering Examination as early as possible.

b. Effective Team Dynamics

- Problems must be addresses immediately to minimize drama.

- Group brainstorming is important.

- The team manager does not necessarily do more work, but must know how to effectively delegate work.

- Conflict can bring about competitiveness.

- Team dynamics vary greatly between undergraduate projects and the workforce because not all students strive for A's.

- Good communications and trust are paramount for success.

- A strong kick-off meeting is important.

- Learn how to read people - it solves problems that haven't happened yet.

- Find out what person excels in what situations.

- Confront issues early and use common sense.

- An effective team is not one that contains all the same type of people; rather, it is a group of people that have different skills.

- Be very careful of developing groups that consists solely of friends. 
c. Ethical and Unethical Behavior in the Engineering Profession

- There is little room for forgiveness with respect to ethical misconduct in engineering.

- Trust must be developed between businesses through meetings.

- People have gone to jail because of "pay to play".

- I thought it would be very difficult for my mentor to find examples of unethical behavior, but he knew many of them.

- If you let something go, it's a slippery slope and people lives could be endangered.

- Unethical behavior usually starts at the top of the ladder.

- The biggest problem is paid vacations or "business trips".

- Don't ever approve anything outside of your area of expertise.

\section{Course Improvements}

Several course improvements related to the teaching of project management skills and the Mentoring Program will be considered for implementation during the 2012 offering of Civil Engineering Fundamentals.

- The importance of developing strong delegation skills as an essential project management characteristic will be stressed, measured and graded. Many of the peer reviews indicated the PMs did an inordinate amount of work. The burden shifted as different members of the group rotated into the PM role.

- A system should be developed through which students can easily and routinely maintain contact with their mentors after Fundamentals has concluded.

- The Mentors Program should be offered to the faculty of the Department as a Program which could be continued throughout the second, third and fourth years of the curriculum. Through this Program, students would maintain contact with their mentors through subsequent undergraduate coursework, including capstone projects, and also into the beginning of their professional careers.

- On-campus events such as meetings sponsored by student chapters of professional organizations could serve as forums where students could meet their mentors and develop stronger professional relationships. Unfortunately, not all mentors live within commuting distance of the campus.

- A Project Manager's Check Off Sheet will be developed and given to students assigned as PMs. This sheet will reflect project management characteristics covered in a lecture. Students will complete and return this Check Off Sheet along with the Final Report associated with their PM project. 
- As noted earlier, PMs comment on the performance and participation of students in their groups is part of the evaluation process. A system will be implemented through which this information is captured and shared with the students at the end of the course. Thereby, students will be able to read the constructive critical comments offered by their PMs regarding their performance in projects throughout the course.

\section{Conclusions}

Civil Engineering Fundamentals strives to establish a solid professional foundation upon which students can begin to build strong careers leading to responsible contributions to society in technical, management and/or leadership positions. The course attempts to accomplish these goals through the introduction of project management skills and the personal 'one-on-one' interaction with practicing civil engineers through a Mentors Program, Many of the logistical aspects of the project management exercises and Mentor Program were improved during the second year of the course. Additional improvements will be implemented as Civil Engineering Fundamentals continues to evolve. 